\title{
An experimental study on the effects of phenocrysts on convection in magmas
}

\author{
Takehiro Koyaguchi ${ }^{\mathrm{a}}$, Mark A. Hallworth ${ }^{\mathrm{b}}$ and Herbert E. Huppert ${ }^{\mathrm{b}}$ \\ ${ }^{a}$ Earthquake Research Institute, University of Tokyo, Tokyo 113, Japan \\ ${ }^{b}$ Institute of Theoretical Geophysics, University of Cambridge, Silver Street, Cambridge CB3 9EW, UK
}

(Received December 9, 1991; revised version accepted June 18, 1992)

\begin{abstract}
Koyaguchi, T., Hallworth, M.A. and Huppert, H.E., 1993. An experimental study on the effects of phenocrysts on convection in magmas. J. Volcanol. Geotherm. Res., 55: 15-32.

The effect of phenocrysts on convection in magma chambers is investigated experimentally using small heavy particles in convecting fluids. The particles are initially uniformly distributed in a fluid which is either heated from below or cooled from above. The system is allowed to evolve, and temperature and particle concentration profiles are measured as functions of time. When the concentration of particles is sufficiently small, convection is basically unaffected by their presence. When the concentration is above a critical value, however, the convective motion is considerably altered. The effect of particles on the subsequent fluid behaviour is different in the cases of heating from below and cooling from above. In the former case, there are strong convective motions confined to a sedimentary layer of decreasing thickness beneath a clear layer which displays rather weak convective motions. With time, the destabilizing increase of temperature in the lower layer overcomes the stabilizing contribution to the bulk density due to the particles and the layer overturns quite suddenly. In the situation of cooling from above, a critical condition separates a case of continual overturn from a case of no overturn at all, with the sedimentary layer falling unimpeded to the bottom. Theoretical analysis suggests that the critical value is determined primarily by the ratio of the contribution to the bulk density of the suspension due to particles to the change in fluid density due to the thermal effect. The size distribution of the particles can also modify the fluid behaviour. Applying our general results to geological situations, we suggest that the presence of relatively small concentrations of phenocrysts can critically influence the mode of convection in magmas.
\end{abstract}

\section{Introduction}

Particle motions in a convecting fluid occur frequently in many geological processes, such as when crystals settle in a convecting magma or during the deposition of volcanic ejecta from pyroclastic flows and eruption columns. In these situations the convective motions play an important role in the settling behaviour of particles and in the formation of the resultant deposits. There have been some theoretical and experimental studies of particle trajectories in

Correspondence to: T. Koyaguchi, Earthquake Research Institute, University of Tokyo, Tokyo 113, Japan. steady cellular convection (Stommel, 1949; Marsh and Maxey, 1985; Weinstein et al., 1988 ) and also in turbulent convection (Huppert and Sparks, 1980; Martin and Nokes, 1988, 1989) some of which have been applied to the settling behaviour of phenocrysts in convecting magmas. One of the most important assumptions in these studies is that the concentration of particles is so small that their presence does not modify the convective motion. Recently, Koyaguchi et al. (1990) have shown experimentally that the presence of particles can greatly influence the convective motion when the particle concentration exceeds a critical value. Because particles generally have 
a different density from the interstitial fluid, their presence changes the bulk density. In addition, sedimentation interfaces can produce vertical heterogeneities in density which can lead to fundamental changes in the form and extent of the convective motions. Many volcanic rocks carry abundant phenocrysts of up to several tens of percent by volume. Previously, their effects have been investigated only in terms of physical properties (e.g., viscosity) of magma (e.g., Marsh, 1981), while the important effects of suspended phenocrysts on convective motions have been neglected in considerations of magma dynamics.

TABLE 1

\section{Nomenclature}

a dimensionless parameter defined in the text a dimensionless parameter defined in the text particle concentration $\left(\mathrm{g} \mathrm{cm}^{-3}\right)$ specific heat capacity of fluid $\left(\mathrm{cal} \mathrm{g}^{-1}=\mathrm{C}^{-1}\right)$ acceleration due to gravity $\left(\mathrm{cm} \mathrm{s}^{-2}\right)$ depth of fluid layer $(\mathrm{cm})$

Prandtl number

heat flux ( $\mathrm{cal} \mathrm{cm} \mathrm{cm}^{-2} \mathrm{~s}^{-1}$ )

heat flux from fluid to the top plate (cal $\mathrm{cm}^{-2} \mathrm{~s}^{-1}$ )

Rayleigh number

initial temperature $\left({ }^{\circ} \mathrm{C}\right)$

temperature of the top plate $\left({ }^{\circ} \mathrm{C}\right)$

temperature of the base plate $\left({ }^{\circ} \mathrm{C}\right)$

temperature of the lower layer $\left({ }^{\circ} \mathrm{C}\right)$

temperature of the upper layer $\left({ }^{\circ} \mathrm{C}\right)$

temperature of the heat exchanger $\left({ }^{\circ} \mathrm{C}\right.$ )

temperature of the bulk system $\left({ }^{\circ} \mathrm{C}\right)$

time (s)

* time for overturn divided by time for the bottom of the interfacial zone to reach the base

descent rate of the bottom of the interfacial zone $(\mathrm{cm}$ $\left.s^{-1}\right)$

$v_{\mathrm{s}} \quad$ Stokes settling velocity $\left(\mathrm{cm} \mathrm{s}^{-1}\right)$

$\alpha$ thermal expansion coefficient $\left({ }^{\circ} \mathrm{C}^{-1}\right)$

$\Delta T$ temperature difference between the initial fluid and the base or top plate $\left({ }^{\circ} \mathrm{C}\right)$

$\Delta \rho$ density difference between the particles and the initial fluid $\left(\mathrm{g} \mathrm{cm}^{-3}\right)$

thermal diffusivity $\left(\mathrm{cm}^{2} \mathrm{~s}^{-1}\right)$

kinematic viscosity $\left(\mathrm{cm}^{2} \mathrm{~s}^{-1}\right)$

a dimensionless constant for convective heat flow density of fluid $\left(\mathrm{g} \mathrm{cm}^{-3}\right)$

bulk density of the lower layer $\left(\mathrm{g} \mathrm{cm}^{-3}\right)$

density of the upper layer $\left(\mathrm{g} \mathrm{cm}^{-3}\right)$

density of the particles $\left(\mathrm{g} \mathrm{cm}^{-3}\right)$
Approaches to quantify the behaviour of particles in convecting fluids depend on whether the convection is laminar or turbulent. The behaviour of particles in steady laminar convection has been investigated in the past by calculating the trajectory of individual particles in the flow. On the other hand, the transport of particles in turbulent convection can at the moment be quantified only by averaged values such as the evolution of bulk particle concentration. Because Rayleigh numbers are likely to be sufficiently large for highly time-dependent convection in many magma chambers (e.g., Huppert and Sparks, 1980; Martin et al., 1987; Carrigan, 1987), we adopt the latter approach. In a turbulently convecting magma, the behaviour of phenocrysts is strongly governed by the ratio of the convective velocity to the Stokes settling velocity. If this ratio greatly exceeds unity, particles in the interior of the fluid are suspended by the fluid motion without settling and their concentration is homogenized (Huppert and Sparks, 1980; Sparks et al., 1984; Martin and Nokes, 1988, 1989). Conversely, as the ratio approaches zero, the relative motions of small particles are governed by low Reynolds number hydrodynamics and they settle at the rate of their Stokes velocity. The convective velocity in a particle-free fluid is expressed as a simple function of the dimensionless Rayleigh and Prandtl numbers (e.g., Turner, 1973). These parameters are defined as:

$R a=g \alpha \Delta T h^{3} / \nu \kappa$

and

$\operatorname{Pr}=\nu / \kappa$

where $g$ is the acceleration due to gravity, $\alpha$ is the thermal expansion coefficient of the fluid, $\Delta T$ is the temperature drop across the fluid layer, $h$ is the depth of the fluid layer, $\nu$ is the kinematic viscosity of the fluid and $\kappa$ is the thermal diffusivity. In the present experiments, the Rayleigh numbers were generally sufficiently large for the convection to be fully 
turbulent under particle-free conditions; nevertheless, the style of convection observed was very different from this. The main aims of this study are to describe the effect of particles on the style of convection and to clarify the parameters that govern it.

First, we present experimental results which describe the evolution of an initially uniform distribution of small heavy particles in a fluid heated from below. The associated theoretical considerations show that the increase in bulk density due to the presence of particles plays an important role in the modification of the convective motions. Second, we describe experiments in which the fluid is cooled from above and show that the style of convection and thermal evolution is different from the heated from below case. The importance of particle size distribution is also discussed, although we have no fully quantitative theory to describe it as yet. Finally, geological applications are briefly discussed.

\section{Experiments heated from below}

\section{Procedure}

The suspensions used were mixtures of silicon carbide grit with water or glycerine solutions. The grit is commercially available in various size grades as a polishing agent and has a particle density of $3.217 \mathrm{~g} \mathrm{~cm}^{-3}$. Most of the experiments were conducted using grade 800 , although some runs were made using grade 1000 and also 800/1000-grade mixtures for comparison. The distribution of settling velocities for these particles in water was determined by the sedigraph technique (Jones et al., 1988 ) and from these velocity distributions we can evaluate the size distribution of particles as shown in Figure 1. The 800 -grade has an effective median diameter of $16 \mu \mathrm{m}$ with a standard deviation of about $3 \mu \mathrm{m}$, and the 1000 grade has an effective median diameter of 5.5 $\mu \mathrm{m}$ with standard deviation of $1.5 \mu \mathrm{m}$, where the effective diameter is the diameter of a

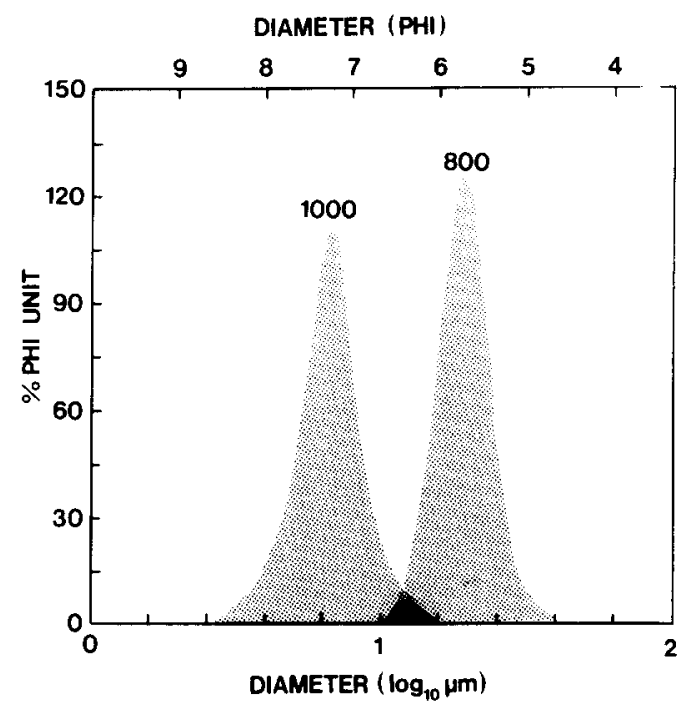

Fig. 1. The probability distribution functions based on mass for diameters of equivalent spherical sand particles for the 800- and 1000-grade silicon carbide particles used in the experiments.

spherical silicon carbide particle that would have the same settling velocity in water at low Reynolds numbers. The Stokes settling velocities for these ranges give a Reynolds number less than $10^{-3}$. In most experiments the solution used was water, which had been treated with a wetting agent $(0.2 \mathrm{wt} . \%$ sodium hexametaphosphate) to inhibit particle aggregation. The glycerine solutions were used to increase the fluid viscosity and thereby to evaluate its effect.

The experimental apparatus used is shown in Figure 2 and consisted of an insulated perspex tank $20 \times 20 \times 46 \mathrm{~cm}$ high, with a metallic base $0.5 \mathrm{~cm}$ thick. The base was bolted to a heat exchanger through which water could be pumped from a temperature-controlled circulator.

The particle concentration was measured using a transmitted-light intensity technique, in which a narrow beam of light was passed from a source, through the suspension, to a detector. The intensity of light received by the detector was found to be a logarithmic function of particle concentration (Beer's law; for 


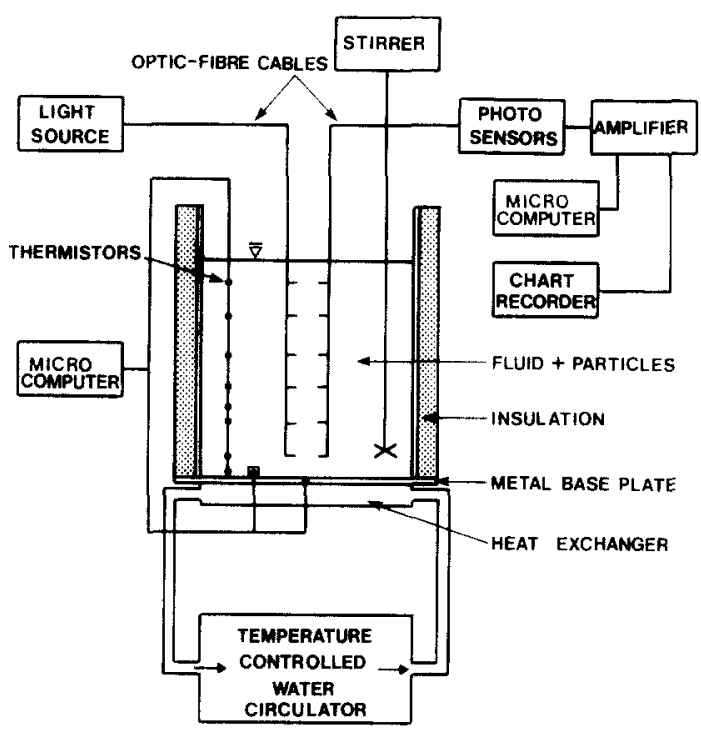

Fig. 2. A schematic diagram of the experimental apparatus used for heating particle suspensions from below.

detail see Davis and Hassen, 1988). Because the relatively high initial concentrations used in our experiments resulted in the total extinction of light across the $20-\mathrm{cm}$ tank width, we developed a system in which a beam of light traversed a distance of only $0.6 \mathrm{~cm}$ of the suspension within the tank by use of optic fibre cables $(2.25 \mathrm{~mm}$ in diameter $)$. The assembly comprised a projector from which light was directed down an optic cable to a small perspex mounting held centrally within the tank. The mounting allowed the emergent beam of light to traverse the gap and impinge upon the end of a similar cable, which then directed the transmitted light out of the tank to a photo diode. In most of the runs, six concentration probes were used (typically at heights of 2.0 , $5.2,8.4,11.6,14.8$ and $18.0 \mathrm{~cm}$ above the base). In order to obtain concentration values in terms of particle wt.\% without the need for any theoretical treatment of voltage output from the transmitted light intensity, the relationship between voltage output and known values of particle concentration was calibrated prior to each experimental run. Accuracy of this method is believed to be within $0.02 \mathrm{wt} . \%$ absolute.

The temperatures of the base plate, $T_{\mathrm{B}}$, and fluid were monitored using thermistors at ten fixed positions; one housed inside the base plate, another fixed to the upper surface of the base plate and the remainder held inside the tank (typically at heights of $0.5,2.0,5.2,6.8$, $8.4,11.6,14.8$ and $18.0 \mathrm{~cm}$ ). Temperature and concentration values were sampled digitally by microcomputer every fifteen seconds throughout each run, and concentrations were additionally monitored continuously in analogue form using chart recorders.

Once calibration of the concentration probes had been completed, water at $40^{\circ} \mathrm{C}$ was circulated through the heat exchanger and the water-particle mixture, typically $21 \mathrm{~cm}$ deep, was stirred until the homogenized suspension attained a nominal starting temperature (typically 9.6 or $26.2^{\circ} \mathrm{C}$ ). The stirrer was then switched off and removed, this point being taken as $t=0$ for each run. Residual motion from the stirring was usually damped within $15 \mathrm{sec}$.

Experiments with systematic variations of the initial concentration of particles, $C_{0}$, and initial temperature of the suspension, $T_{0}$, and hence $\Delta T\left(=T_{\mathrm{B}}-T_{0}\right)$, were carried out. In practice, the temperature of the base plate normally equilibriated within 2 minutes from the start of a run to a value roughly between the initial suspension temperature and the temperature of the water circulating through the heat exchanger, $T_{\mathrm{R}}$. This value could be measured from the thermistor within the base plate and was found to rise generally by one or two degrees during an experiment. The value of $\Delta T$ in the experiments with initial fluid temperatures of 9.6 and $26.2^{\circ} \mathrm{C}$ is approximately 24 and $9^{\circ} \mathrm{C}$, respectively. The conditions of representative runs and their calculated Rayleigh and Prandtl numbers are listed in Table 2. 
TABLE 2

List of the experimental conditions and the values of dimensionless parameters

\begin{tabular}{|c|c|c|c|c|c|}
\hline Fluid & $\begin{array}{l}\text { Particle } \\
\text { grade }\end{array}$ & $\begin{array}{l}\text { Range of particle } \\
\text { concentrations (wt.\%) }\end{array}$ & $\begin{array}{l}\text { Nominal temperature } \\
\text { difference }\left({ }^{\circ} \mathrm{C}\right)\end{array}$ & $\mathrm{Ra}$ & $\begin{array}{l}\text { Parameter } \\
A^{*}\end{array}$ \\
\hline
\end{tabular}

A. Heating from below

\begin{tabular}{|c|c|c|c|c|}
\hline water & $\begin{array}{c}800 \\
1000 \\
800+1000\end{array}$ & $\begin{array}{c}0.06-1.2 \\
0.2-0.6 \\
0.2-0.6 \text { for each grade }\end{array}$ & 9 & $2 \times 10^{9}$ \\
\hline & $\begin{array}{c}800 \\
1000 \\
800+1000\end{array}$ & $\begin{array}{c}0.06-1.2 \\
0.2-0.6 \\
0.2-0.6 \text { for each grade }\end{array}$ & 24 & $2 \times 10^{9}$ \\
\hline $\begin{array}{l}25 \% \text { glycerine } \\
50 \% \text { glycerine }\end{array}$ & $\begin{array}{l}800 \\
800\end{array}$ & $\begin{array}{l}0.2-0.6 \\
0.2-0.6\end{array}$ & $\begin{array}{r}9 \\
24 \\
24\end{array}$ & $\begin{array}{l}1 \times 10^{9} \\
1 \times 10^{9} \\
4 \times 10^{8}\end{array}$ \\
\hline
\end{tabular}

B. Cooling from above

\begin{tabular}{|c|c|c|c|c|}
\hline Mntar & 800 & $009-12$ & $\begin{array}{l}13 \\
24\end{array}$ & $\begin{array}{l}9 \times 10^{8} \\
2 \times 10^{9}\end{array}$ \\
\hline & 800 & $0.09-1.2$ & & \\
\hline
\end{tabular}

* A dimensionless parameter defined in the text. In the calculation the values for $v$ of 800 -grade in water, $25 \%$ glycerine and $50 \%$ glycerine are assumed to be $0.035,0.015$ and $0.005 \mathrm{~cm} \mathrm{~s}^{-1}$ respectively, and that of 1000 -grade in water to be $0.004 \mathrm{~cm} \mathrm{~s}$.

Results

\section{Descriptions of representative experiments}

Observation of the experiments and analyses of temperature and concentration profiles revealed systematic changes in the settling behaviour of the particles and thermal evolution of the fluid with the variation of experimental conditions. The most important result is that the presence of relatively small amounts of particles $(<1 \mathrm{wt} . \%)$ can largely influence the overall convective motion. We will describe the results of three representative experiments (A, $B$ and $C$ ) which exhibit different evolutionary characteristics. The three experiments all began with an initial fluid temperature of $9.6^{\circ} \mathrm{C}\left(\Delta T \sim 24^{\circ} \mathrm{C}\right)$ but had different starting concentrations, $C_{0}$, of $0.06,0.3$ and $1.2 \mathrm{wt} . \%$ particles, respectively.

Experiment A. At low particle concentration, highly time-dependent convection was observed throughout the tank, and the particle concentration remained nearly uniform except for a slight decrease at the top of the fluid layer (in a zone a few $\mathrm{cm}$ in depth). The fluid tem- perature was also uniform thoughout the tank and increased with time, while the particle concentration decreased with time. This distribution and evolution of particle concentration has been explained by Martin and Nokes (1988, 1989). Particles were uniformly distributed due to turbulent convection thoughout most of the depth of fluid where the rootmean-squared convective velocity greatly exceeded the Stokes settling velocity. In this region individual particles behaved as passive tracers of the flow. On the other hand particles settled out with their full Stokes velocity at the basal boundary where the convective velocity is zero. The change of particle concentration, $C$, with time, $t$, is expressed by Martin and Nokes $(1988,1989)$ as:

$C=C_{0} \exp \left(-v_{\mathrm{s}} t / h\right)$

where $v_{\mathrm{s}}$ is the Stokes settling velocity and $h$ is the layer depth. The rate of decrease in particle concentration in this experiment was found to agree fairly well with this equation. The most important characteristic of this model is that the evolution of particle concentration is independent of the intensity of, or driving force 


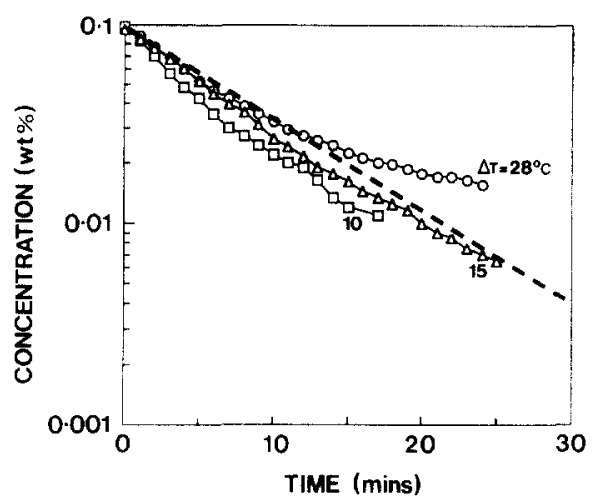

Fig. 3. Evolution of particle concentration as a function of time in the low concentration regime described for Experiment $A$. The dashed curve represents the theoretical evolution of concentration given by equation ( 3 ) from an initial value of $0.10 \mathrm{wt} \%, h=20.0 \mathrm{~cm}$ and $v_{\mathrm{s}}=0.035 \mathrm{~cm}$ $\mathrm{s}^{-1}$. Experimental data are plotted for values of $\Delta T$ of $28^{\circ} \mathrm{C}$ (O), $15^{\circ} \mathrm{C}(\triangle)$ and $6^{\circ} \mathrm{C}(\square)$.

for, convection so long as the convection is turbulent. Some preliminary experiments, where the system was simultaneously cooled from above and heated from below with variable $\Delta T$ from 6 to $28^{\circ} \mathrm{C}$ and a constant initial concentration of $0.1 \mathrm{wt} . \%$, were carried out in order to test the effect of the intensity of convection. The results suggested that the style of convection and behaviour of the particles are qualitatively identical to experiment $\mathrm{A}$, but the rate of decrease in particle concentration decreased slightly as the intensity of convection increased (i.e. $\Delta T$ was increased) (Fig. 3 ). This implies that the model of Martin and Nokes $(1988,1989)$ needs some refinement, but such treatment falls outside the scope of the present study.

Experiment $B$. In an experiment with the higher initial particle concentration of $0.3 \mathrm{wt} . \%$, turbulent convection throughout the whole tank was suppressed at an early stage, and mostly confined to a sedimenting layer separated from an upper clear layer by an interfacial region (Fig. 4a). The particle concentration of the lower layer was nearly uniform due to strong convective mixing; the temperature increased with time while the particle concentration slightly decreased with time. The overlying interfacial region descended with a rate similar to the Stokes settling velocity and increased in thickness mainly due to the slight variation in the settling velocity of individual particles due to their different sizes (Davis and Hassen, 1988; Huppert et al., 1991). The particle concentration gradient of the interfacial region was initially strong enough to overcome the destabilizing thermal contribution to the bulk density caused by heating at its base. This stable bulk-density gradient inhibited convection, and produced a stagnant interfacial region insulating the overlying clear fluid from the heated suspension below. The temperature of the clear region increased only slightly during this stage due to the release of warm fluid at the top of the descending interfacial zone. This resulted in relatively weak convective motions in the clear upper layer that were sufficiently strong, however, to homogenize the temperature profile. As the interfacial zone descended, its thickness increased due to polydispersion which resulted in a weakening of the stabilizing compositional gradient. Eventually, the temperature of the lower layer became sufficiently large that, despite the stabilizing presence of particles, the bulk density of the lower layer became less than that of the upper layer. At that time ( $9 \frac{1}{2}$ minutes for experiment B) the whole system rapidly overturned (Fig. 4b), and re-established uniform temperature and concentration profiles throughout the tank. The particle concentration at this stage was much lower (about $0.05 \mathrm{wt} . \%$ ) than the initial concentration due to the irreversible loss of sedimented particles on the base of the tank. This remaining, more dilute suspension then began to evolve (Fig. $4 \mathrm{c}$ ) in exactly the same way until a second overturn occurred, after which the rehomogenized particle concentration was low enough to enter the uniform settling regime already described for experiment A.

The temperature and concentration evolutions at specific heights are shown in Figure 5. 
This form of data presentation is more readily understood with reference to the schematic plots in Figure 6, which presents the evolution of temperature and concentration at 4 differ-

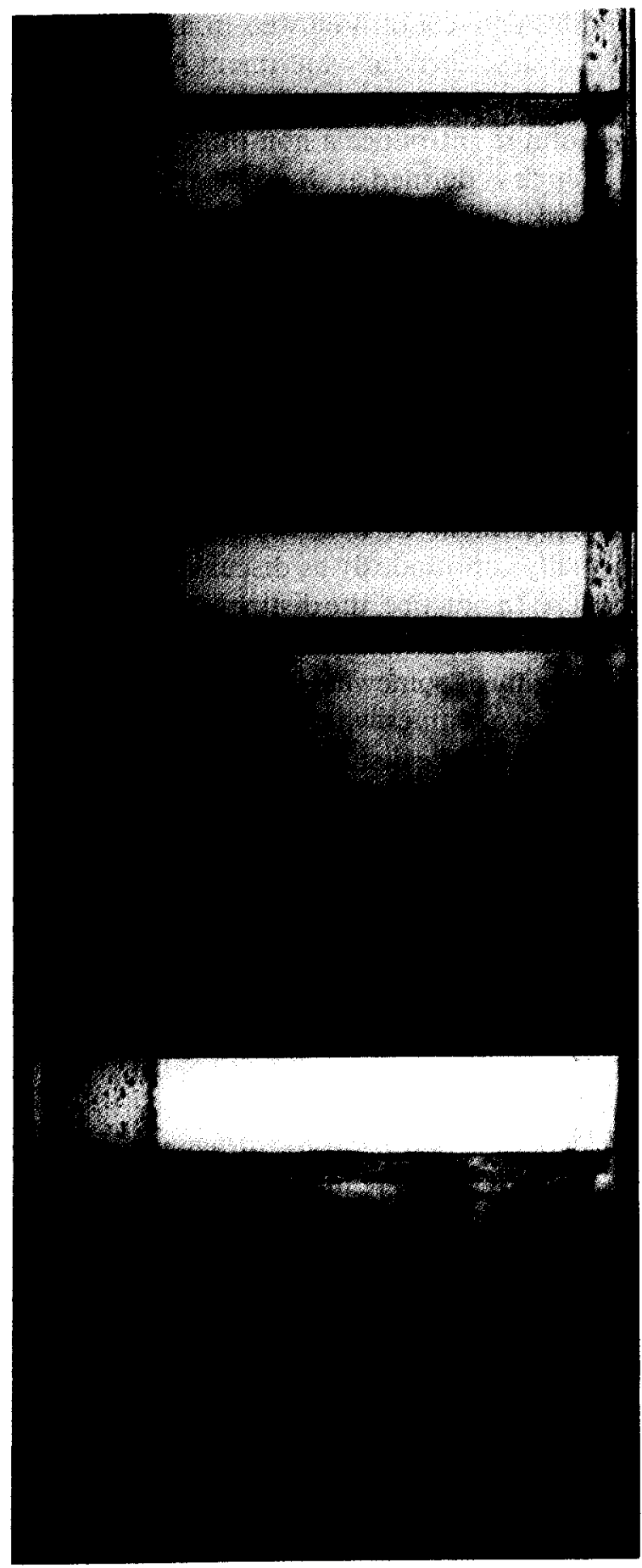

ent heights marked A, B, C and D (Fig. 6c). This representation serves to define the pertinent features of the evolution, which will prove useful when comparing runs with different experimental conditions. The system begins at time 0 as a homogeneous suspension of concentration $C_{0}$ and temperature $T_{0}$. As the interfacial region descends, it moves past the probes at $\mathrm{A}$. The passage of the base of the interfacial zone is marked by points $P_{\mathrm{A}}$ in Figure $6 \mathrm{a}$ and $\mathrm{b}$. The probes then measure decreasing values of temperature and concentration as the diffuse interfacial region passes before they emerge into the upper clear layer at $Q_{\mathrm{A}}$. The temperature of the lower layer continues to rise, and the coincidence of measurements at points within this layer indicates that it is well mixed by the turbulent convection. At $P_{\mathrm{B}}$ and $P_{\mathrm{C}}$ the base of the interfacial zone reaches probes $B$ and $C$, respectively, and at $Q_{\mathrm{B}}$ the top of the interfacial zone reaches probe $B$. Using these data, we can estimate the descent rate of the base of the interfacial zone, as is shown in Figure $5 \mathrm{c}$. We note that in this example the first overturn occurs before the probes at $C$ emerge into the upper layer. The details of a subsequent overturn are also shown in Figure 6.

Experiment $C$. When the particle concentration was greater than approximately $0.5 \mathrm{wt} . \%$, overturn did not occur even when the bottom of the interfacial zone reached the base of the tank. The fluid behaviour in the initial stage of this experiment was similar to that in experiment $B$; the interfacial zone descended leaving

Fig. 4. A photographic sequence showing the overturning of a sedimenting layer heated from below as described in the text for Experiment B. (a) Formation of a clear region above a descending interface. (b) Heating at the base leads to a decrease in the bulk density of the lower layer. This photograph shows the onset of overturn as the interface breaks down and warmer, particle-rich fluid from the lower layer rises into the overlying, cooler clear layer. (c) The overturn is complete. Rehomogenisation of the fluid layer and sedimentation begins again. 


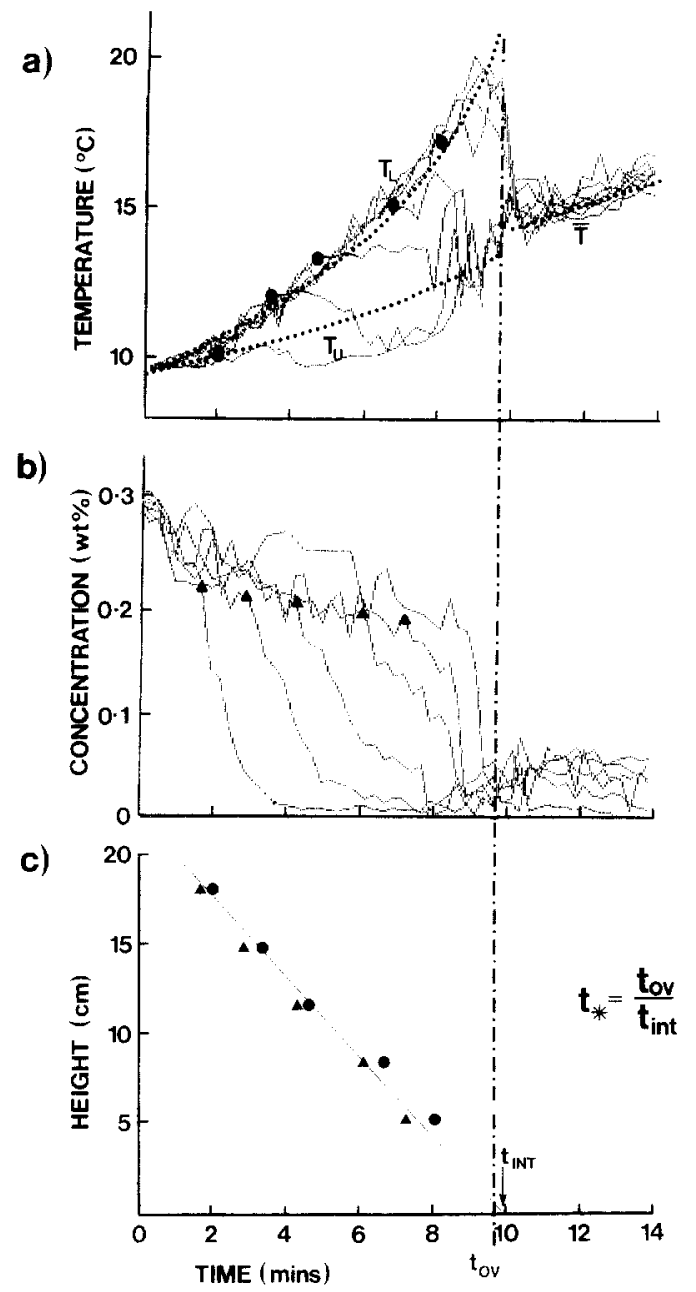

Fig. 5. Experimentally obtained curves from probes at 6 fixed heights in Experiment B showing the evolutions of: (a) temperature; (b) concentration; and (c) height of the interface as functions of time. Interpretation of the data is explained schematically in Fig. 6, and allows the descent rate of the base of the interface $v$ to be estimated by transposing the points of departure of probe traces from the lower layer evolution trends (denoted by $O$ in a and $\Delta$ in b) to the height-time plot (c). Theoretical predictions from the analyses presented in the text for the temperature evolution of the upper and lower layers, and the bulk system after overturn are superimposed as dashed curves in Fig. 5a, using $v=0.035 \mathrm{~cm} \mathrm{~s}^{-1}, \Delta T=24^{\circ} \mathrm{C}$.

a clear layer above. After the bottom of the interfacial zone had reached the base of the tank, further sedimentation continued and resulted in a decreasing particle concentration in the fluid just above the base of the tank. Eventually, the particle concentration of the interfa- cial zone became sufficiently small for the bulk density to fall to a value lower than that of the upper clear layer, and overturn of the remaining part of the interfacial zone occurred. Subsequently, small-scale overturns and then continuous convection followed in a similar way to that described for experiment $\mathrm{A}$.

In order to compare different experiments it is useful to introduce a non-dimensional time $t_{*}$, which is defined as the time at which overturn takes place divided by the projected time at which the bottom of the interface would have reached the base of the tank had overturning not taken place. Both quantitities can easily be obtained from the experimental results shown in Figure 5. If $t_{*}>1$, overturn does not occur before the bottom of the interfacial zone reaches the base of the tank, as was described for experiment C. If $t_{*} \ll 1$, overturn occurs virtually continuously as discussed for experiment $A$. In practice, the distinction between the continuous convection regime and the overturn regime is somewhat blurred because of the convective plumes which eminate from the irregular interface distorted by the turbulence in the lower layer.

\section{The factors governing $t_{*}$}

The results from experiments with different values of $\Delta T$ and viscosity are compared in Figure 7 which presents plots of $t_{*}$ as a function of particle concentration.

The effect of temperature difference. Experiments with the same initial particle concentrations but with two different initial fluid temperatures of $9.6^{\circ} \mathrm{C}$ and $26.2^{\circ} \mathrm{C}$ were carried out to evaluate the effect of changing the temperature difference between the base plate and the fluid ( $\triangle T=24^{\circ} \mathrm{C}$ and $9^{\circ} \mathrm{C}$, respectively). The results are qualitatively similar, but the timing of the overturn is delayed for runs with $\Delta T=9^{\circ} \mathrm{C}$ when compared to the equivalent concentration runs with $\Delta T=24^{\circ} \mathrm{C}$, as clearly evident in Figure 7. 
a) TEMPERATURE

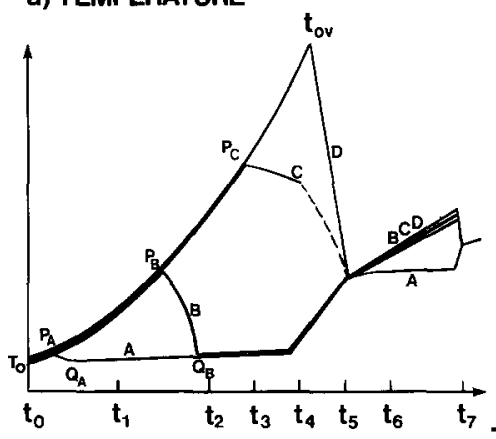

b) CONCENTRATION

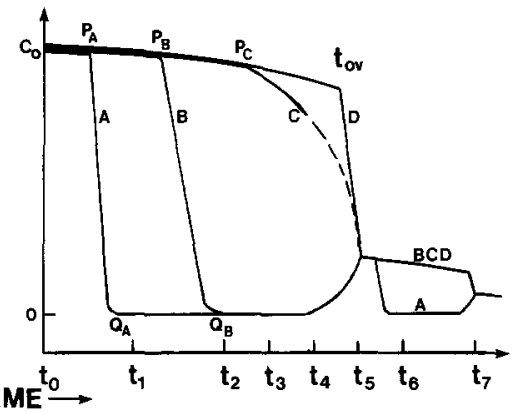

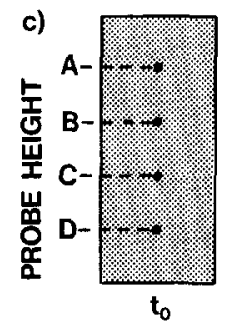
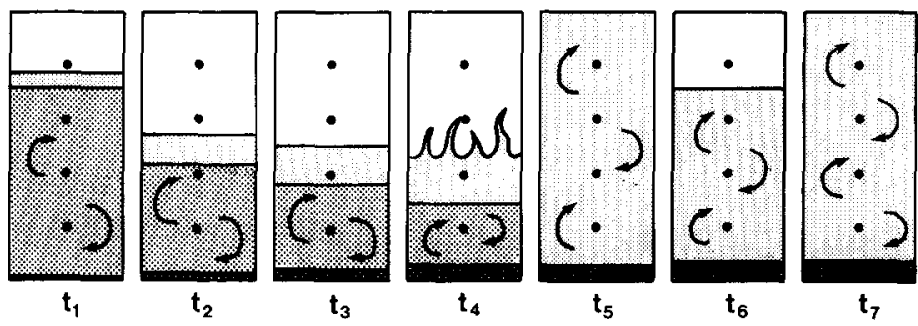

Fig. 6. Schematic illustration showing plots of: (a) temperature and; (b) concentration as functions of time for 4 fixed probe positions marked $A, B, C$ and $D$ in (c), which displays the evolutionary stages of a sedimenting system being heated from below and overturning.

The effect of varying the viscosity of the fluid. Experiments were also conducted with aqueous glycerine solutions of $25 \%$ and $50 \%$ in order to assess the role of fluid viscosity. Values of viscosity and density for these solutions are given in Table 3. Experiments with four different initial particle concentrations $(0.2,0.3,0.45$ and $0.6 \mathrm{wt} . \%$ ) were carried out for each solution. The initial fluid temperatures were $9.6^{\circ} \mathrm{C}$ and $26.2^{\circ} \mathrm{C}$ in experiments with $25 \%$ glycerine and $9.6^{\circ} \mathrm{C}$ in those with $50 \%$ glycerine.

The experimental results of runs with $25 \%$ glycerine were qualitatively similar to those with water. Because of the higher viscosity, the

TABLE 3

Viscosity and density of the aqueous glycerine solutions used in the experiments

\begin{tabular}{lll}
\hline Concentration & $\begin{array}{l}\text { Density } \\
\text { at } 20^{\circ} \mathrm{C} \\
\left(\mathrm{g} \mathrm{cm}^{-3}\right)\end{array}$ & $\begin{array}{l}\text { Kinematic } \\
\text { viscosity at } 20^{\circ} \mathrm{C} \\
\left(\mathrm{cm}^{2} \mathrm{~s}^{-1}\right)\end{array}$ \\
\hline $25 \%$ & 1.059 & $1.946 \times 10^{-2}$ \\
$50 \%$ & 1.125 & $5.364 \times 10^{-2}$ \\
\hline
\end{tabular}

particle settling velocity decreased, which resulted in a comparative delay for the overturn (15-20 min from the beginning of the run). The relationship between $t_{*}$ and particle concentration systematically deviated from that found for the runs using water. The observed $t_{*}$ for the same particle concentration is smaller in glycerine solutions than in water, as is evident on comparing the results in Figure $7 \mathrm{a}$ with those in Figure $7 \mathrm{~b}$.

The behaviour of fluid in the runs using 50\% glycerine was qualitatively different from that using water or $25 \%$ glycerine. The continuous overturn regime was observed at higher initial particle concentrations (up to $0.2 \mathrm{wt} . \%$ ) than the experiments using water (for which continuous overturn occured for initial particle concentrations below a figure between 0.06 and $0.09 \mathrm{wt} . \%$ dependent on the initial temperature difference). At concentrations greater than $0.2 \mathrm{wt} . \%$ overturn was observed after the formation of a clear layer approximately 30-40 min from the beginning. Subsequently (approximately $40-50 \mathrm{~min}$ from the beginning), 

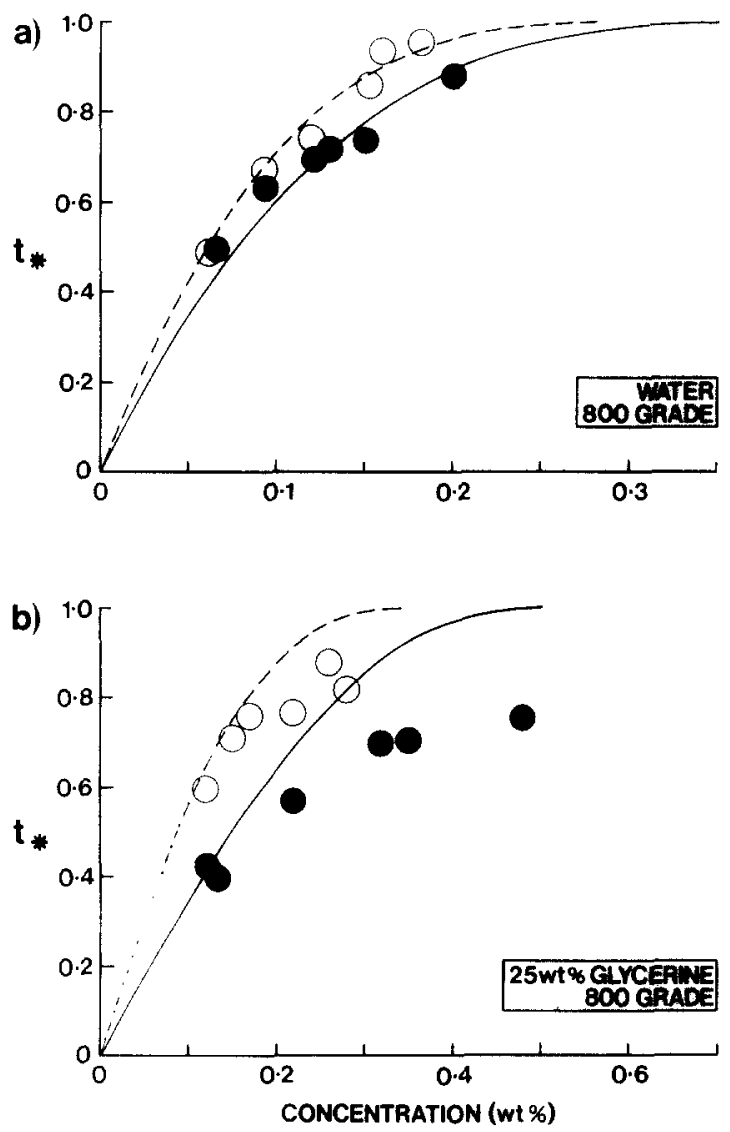

Fig. 7. Normalised time for overturn $\left(t_{*}=v t_{\mathrm{ov}} / h\right)$ as a function of particle concentration, for experiments heated from below using (a) 800-grade in water and (b) 800 grade in $25 \mathrm{wt} . \%$ glycerine solution. Open and closed symbols represent experiments conducted at $\Delta T$ values of $9^{\circ} \mathrm{C}$ and $24^{\circ} \mathrm{C}$, respectively. Measured values of the concentration just prior to overturn are used rather than the initial concentrations as discussed in the text. Theoretical values evaluated from equation (13) are plotted as solid curves for $\Delta T=24^{\circ} \mathrm{C}$ and as dashed curves for $\Delta T=9^{\circ} \mathrm{C}$.

a quasi-steady layered structure was formed. This layered structure was composed of an upper clear layer (typically $2 \mathrm{~cm}$ in depth), an interfacial zone with a particle concentration

\section{TABLE 4}

Values of parameters used in the calculations

$\alpha=2.1 \times 10^{-4}\left({ }^{\circ} \mathrm{C}^{-1}\right)$

$\kappa=1.45 \times 10^{-3}\left(\mathrm{~cm}^{2} \mathrm{~s}^{-1}\right)$

$\nu=1.0 \times 10^{-2}\left(\mathrm{~cm}^{2} \mathrm{~s}^{-1}\right)$

$g=980\left(\mathrm{~cm} \mathrm{~s}^{-2}\right)$ gradient (typically $5 \mathrm{~cm}$ in depth) and a lower, nearly uniform, suspension layer. Cellular convection was observed in both the upper and lower layers. Because of the high viscosity, there was a considerable influence on the fluid motion in the tank from the presence of the particle concentration probes and thermistors. Accordingly quantitative measurements of particle concentration and temperature could not be made for these experiments. The observations from outside the tank indicated that the descent rate of the interfacial zone was much slower than the settling velocity of the particles.

The effect of particle size distribution. Experiments using 1000-grade and the bimodal size mixture of 800 - and 1000-grade were carried out to investigate the effect of particle size distribution. The 1000-grade has a smaller median size and hence the interfacial zone descends at a lower rate. In addition, it is more polydisperse which leads to a greater broadening of the interface.

The results of the experiments using 1000grade were qualitatively similar to those using 800 -grade, in that an upper clear layer developed above a sedimenting layer of decreasing thickness which subsequently overturned. There were, however, some quantitative differences between the experiments using 1000grade compared to those using 800-grade under comparable experimental conditions. First, the time for overturn was considerably increased (e.g., 14 minutes compared with 8.5 minutes for an experiment using 800-grade with identical values of $C_{0}$ and $\Delta T$ ). Second, the rate of decrease in particle concentration within the interfacial zone was much higher. Temperatures were observed to rise in the lower layer, but became almost constant at given heights in the interfacial zone. These results indicate an increased compositional gradient within the interfacial zone, tending to inhibit overturn. It is suggested that both the rate of descent and the rate of thickening of the interfacial zone, which depend critically on par- 
ticle size and distribution, play a large role in the concentration and temperature evolution of the system.

Eighteen runs using a mixture of 800 - and 1000 -grade were carried out to investigate the effect of bimodal size distribution. The temperature evolution of a representative experiment is shown in Figure 8. In these runs, two overturns were observed corresponding to the two modes of particle size. As particles settled out, two interfacial zones separating three layers were formed. The lowermost layer was composed of a suspended mixture of 800 - and 1000 -grade. The middle layer was composed of a suspension of 1000-grade, whilst the uppermost layer was clear. The temperature of the lowermost suspension increased with time which eventually caused it to become less dense than the middle suspension layer. Overturn between the lower and middle layers then occurred approximately $10 \mathrm{~min}$ from the beginning of the run. Because this overturn was essentially confined to the lower and middle layers, the temperature of the uppermost layer increased only slightly. The temperature of the suspension layer (a mixture of 1000- and a small amount of 800-grade) fluctuated immediately after this overturn due to minor overturns accompanying the settling of 800-grade. Subsequently, the temperature of the suspension layer increased and another overturn oc-

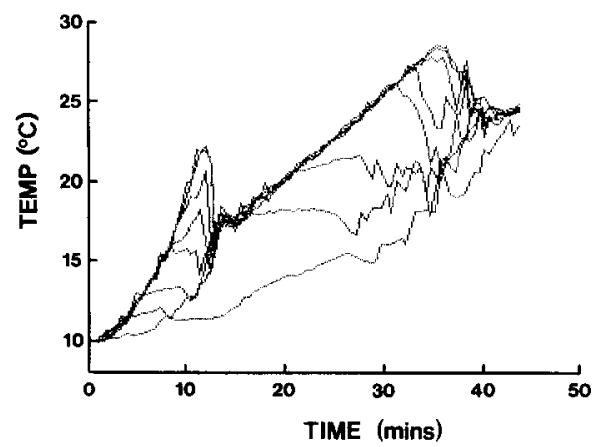

Fig. 8. Representative plot of temperature as a function of time for an experiment using a fifty-fifty mixture of 800 and 1000 -grade particles with $\Delta T=24^{\circ} \mathrm{C}$ and $C_{0}=1.24$ wt. $\%$. curred between the suspension layer and the clear layer approximately $35 \mathrm{~min}$ from the beginning of the runs. The timing of the first major overturn $(\sim 10 \mathrm{~min})$ was similar to that for experiments with the same amount of 800 grade alone, whereas the timing of the second major overturn $(\sim 35 \mathrm{~min})$ was much delayed compared with the experiments using 1000grade alone $(\sim 15 \mathrm{~min})$. This is because the presence of 800 -grade particles in the initial lower layer retarded the heat transfer to the middle layer. Although the phenomena observed in the bimodal size distribution experiments are too complex for a quantitative model to be established yet, it should be emphasized that the particle size distribution greatly influences the style of convection and temperature evolution.

\section{Theoretical model}

For simplicity we assume that the particles are all of one size, because this captures the essential features of the phenomena observed. In this case, two layers form as the particles settle: an upper clear layer and a lower suspension layer. The overall stratification is initially stable, because the bulk density of the lower layer is greater than that of the upper layer due to the presence of particles. As the interfacial zone descends at a constant velocity the temperature of the lower layer increases, while the temperature of the upper layer increases only slightly. Thus the lower layer may become sufficiently hot for its density to fall below that of the upper layer, and overturn then occurs. We now present a simple model which predicts the temperature evolution of the lower layer, $T_{\mathrm{L}}$, the upper layer, $T_{\mathrm{U}}$, and the timing of the overturn. A complementary treatment is presented in Huppert (1991).

The temperature of the lower layer. The experimental results suggest that the lower layer undergoes unsteady convection driven by heating from below. Under this condition, the 
heat flux from the base of the tank to the lower layer can be expressed as (e.g., Turner, 1973):

$q=\rho_{\mathrm{F}} \mathcal{C}_{\mathrm{P}} \gamma\left(\frac{\alpha g \kappa^{2}}{\nu}\right)^{1 / 3}\left(T_{\mathrm{B}}-T_{\mathrm{L}}\right)^{4 / 3}$

where $\rho_{\mathrm{F}}$ is the density of the fluid, $c_{\mathrm{P}}$ is the specific heat, $\gamma$ is a dimensionless constant, the value of which has been determined empirically to be $\sim 0.1$ at relatively high Rayleigh numbers (e.g., Katsaros et al., 1977; Denton and Wood, 1979) and values for pure water for these parameters can be used at the low particle concentrations employed in our experiments. Because the interface is defined as the top of the lower layer, as it descends heated fluid from the lower layer is left behind and incorporated into the upper layer. In this case the heat conservation equation for the lower layer is:

$q=c_{\mathrm{P}} \rho_{\mathrm{F}}(h-v t) \frac{\mathrm{d} T_{\mathrm{L}}}{\mathrm{d} t}$

From equations (4) and (5), the temperature of the lower layer as a function of time can be expressed as:

$$
\begin{aligned}
T_{\mathrm{L}}(t) & =T_{\mathrm{B}}-\left\{\left(T_{\mathrm{B}}-T_{0}\right)^{-1 / 3}\right. \\
& \left.-\frac{\gamma}{3 v}\left(\frac{\alpha g \kappa^{2}}{\nu}\right)^{1 / 3} \ln \left(1-\frac{v t}{h}\right)\right\}^{-3}
\end{aligned}
$$

The validity of this model can be tested against the experimental data, because we can independently obtain $T_{\mathrm{L}}$ and $v$ from the temperature and particle concentration profiles. The temperature evolution, which is calculated using the observed value of $v$, agrees well with the experimentally observed data, as can be seen in Figure 5a.

The temperature of the upper layer. As the interface descends, heated fluid is incorporated into the upper layer. On the assumption that the effect of heat conduction across the interfacial zone is negligible and that the upper layer is homogeneously mixed, a heat budget calculation for the lower layer yields:

$\frac{\mathrm{d} T_{\mathrm{U}}}{\mathrm{d} t}=\frac{1}{t}\left(T_{\mathrm{L}}-T_{\mathrm{I}}\right)$

which, with the initial condition $T_{\mathrm{L}}=T_{\mathrm{U}}$, can be written as:

$T_{\mathrm{U}}=\frac{1}{t} \int_{0}^{t} T_{\mathrm{L}} \mathrm{d} t$

While the solution of this equation can be obtained analytically in terms of exponential integrals, it is easier to present the results numerically (Fig. 5a). This indicates that the rate of increase in $T_{\mathrm{U}}$ with time is considerably smaller than that of $T_{\mathrm{L}}$ because the decrease in volume of the lower layer with time contributes significantly to the rapid increase in $T_{\mathrm{L}}$.

The temperature of the bulk system. Once homogenization of the system has occurred, the bulk temperature, $\bar{T}$, can be expressed in terms of the re-initialised time, $t^{\prime}$, as:

$\bar{T}=T_{\mathrm{B}}-\left\{\left(T_{\mathrm{B}}-T_{\mathrm{o}}^{\prime}\right)^{-1 / 3}+\frac{\gamma t^{\prime}}{3 h}\left(\frac{\alpha g \kappa^{2}}{\nu}\right)^{1 / 3}\right\}^{-3}$

where $T_{\circ}^{\prime}$ is the uniform temperature at $t^{\prime}=0$. This relationship is plotted on Figure 5a.

The timing of overturn. The bulk density of the lower layer $\rho_{\mathrm{L}}$ can be expressed as:

$\frac{1}{\rho_{\mathrm{L}}}=\frac{C}{\rho_{\mathrm{P}}}+\frac{1-C}{\rho_{\mathrm{F}}}$

where $C$ is the particle concentration expressed as a mass fraction, $\rho_{\mathrm{P}}$ is the density of the particles and $\rho_{\mathrm{F}}$ is the density of the fluid in the lower layer. If we refer the densities and the temperatures to those of the upper layer, the density of the fluid in the lower layer can be expressed as:

$\rho_{\mathrm{F}}=\rho_{\mathrm{U}}\left\{1-\alpha\left(T_{\mathrm{L}}-T_{\mathrm{U}}\right)\right\}$

where $\rho_{\mathrm{U}}$ is the density of the fluid in the upper 
layer. The overturn occurs when the bulk density of the lower layer is equal to the density of the clear fluid in the upper layer. From equations (9) and (10), the critical temperature in the lower layer at the overturn, $T_{\mathrm{L}}^{*}$, is given as:

$$
\begin{aligned}
T_{\mathrm{L}}^{*} & =T_{\mathrm{U}}+\frac{C\left(\rho_{\mathrm{P}}-\rho_{\mathrm{U}}\right)}{\alpha \rho_{\mathrm{P}}\left(1-C \rho_{\mathrm{U}} / \rho_{\mathrm{P}}\right)} \\
& \sim T_{\mathrm{U}}+\frac{C\left(\rho_{\mathrm{P}}-\rho_{\mathrm{U}}\right)}{\alpha \rho_{\mathrm{P}}} \quad(C \ll 1)
\end{aligned}
$$

From equation (6) the normalized time, $t_{*}$, can be written as:

$$
\begin{aligned}
t_{*} & =1-\exp \left\{-\frac{3 v}{\gamma}\left(\frac{\nu}{\alpha g \kappa^{2}}\right)^{1 / 3} \times\left[\left(T_{\mathrm{B}}-T_{\mathrm{L}}^{*}\right)^{-1 / 3}\right.\right. \\
& \left.\left.-\left(T_{\mathrm{B}}-T_{0}\right)^{-1 / 3}\right]\right\}
\end{aligned}
$$

If we make the approximation that $T_{\mathrm{U}} \approx T_{0}$, which is valid because the temperature of the upper layer increases only slightly, equation (12) along with equation (11b) can be approximated as:

$$
\begin{aligned}
t_{*} & =1-\exp \left[-\frac{3 v}{\gamma}\left(\frac{\nu}{\alpha g \kappa^{2}}\right)^{1 / 3}\right. \\
& \left.\times\left\{\left(\Delta T-\frac{C \Delta \rho}{\alpha \rho_{\mathrm{P}}}\right)^{-1 / 3}-\Delta T^{-1 / 3}\right\}\right]
\end{aligned}
$$

where $\Delta \rho$ is the difference in density between the particles and the initial fluid and $\Delta T=T_{\mathrm{B}}-\mathrm{T}_{0}$. This equation can be rewritten using two dimensionless parameters, $A$ and $B$, as:

$t_{*}=1-\exp \left[-A\left\{(1-B)^{-1 / 3}-1\right\}\right]$

where

$A=3 R a^{-1 / 3}(h / \kappa \gamma) v$

in terms of the Rayleigh number $R a=\alpha g$ $\Delta T h^{3} / \kappa \nu$ and:

$B=C \Delta \rho / \rho_{\mathrm{p}} \alpha \Delta T$

The parameter $A$ represents the ratio of the heat budget of the lower layer due to the de- scent rate of the interface to that supplied by the heating at the base. The parameter $B$ represents the increase in bulk density due to the presence of particles divided by the decrease in the fluid density due to the thermal effect. The critical condition $t_{*}=1$ is then given by $B=1$, with $B<1$ required for $t_{*}<1$. For any values of $\Delta T$ and $\rho_{\mathrm{P}}$, the critical particle concentration for overturn to occur can be estimated by equation (14c). The value of $A$ determines the shape of the curve of $t_{*}$ as a function of concentration in $0<t_{*}<1$. As $A$ decreases, $t_{*}$ for given values of $B$ also decreases. The lower value of $t_{*}$ in the experiments with higher viscosity (Fig. $7 b$ ) can be qualitatively explained by smaller $v$ and hence smaller values of $A$ (see Table 2 ). This model agrees fairly well with the experiments when $t_{*}>0.5$; however, it is less valid for $t_{*}<0.5$, because convection in the lower layer tends to overshoot into the interfacial zone or the upper layer. Furthermore, in our idealized model, particle concentration in the lower layer is considered to be constant, because particles settle out with the same velocity as the interfacial zone descends. In reality, however, this concentration decreases with time, mainly because larger particles are progressively removed from the sedimenting layer. The agreement between theory and expriment is improved if the concentration just before overturn is used rather than the initial concentration.

\section{Experiments cooled from above}

\section{Procedure}

A perspex tank $20 \times 20 \times 18.8 \mathrm{~cm}$ deep with a brass cooling plate at the top was used in all the experiments cooled from above. Temperatures at the surface and interior of the plate and those inside the tank (typically at heights of $2.0,5.0,8.0,9.5,11.0,17.0$ and $18.0 \mathrm{~cm}$ ) were measured by thermistors, and particle concentrations at heights of 2.0, 5.0, 8.0, 11.0 and 17.0 
$\mathrm{cm}$ were measured by the optical device already described. Ten different initial particle concentrations were used, ranging from 0.09 wt. $\%$ to $1.2 \mathrm{wt} . \%$. For each concentration, experiments were conducted at two different initial fluid tempertures, $T_{0}$, typically $22^{\circ} \mathrm{C}$ and $35^{\circ} \mathrm{C}$. Water at $6^{\circ} \mathrm{C}$ was circulated through the heat exchanger and cooling plate. When the plate was positioned in contact with the fluid, its temperature, $T_{\mathrm{A}}$, was found to rise in the first two minutes of any run from $6^{\circ} \mathrm{C}$ to approximately $9^{\circ} \mathrm{C}$ when $T_{0}=22^{\circ} \mathrm{C}$, and from $6^{\circ} \mathrm{C}$ to approximately $11^{\circ} \mathrm{C}$ when $T_{0}=35^{\circ} \mathrm{C}$, thereafter remaining almost constant. This gave approximate initial values of $\Delta T$ of $13^{\circ} \mathrm{C}$ and $24^{\circ} \mathrm{C}$ respectively. Control experiments were also performed at each initial concentration with no cooling from above (i.e. $\Delta T=0$ ) to determine the sedimentation rate in the absence of convection.

\section{Results}

Unlike the case of heating from below, the sudden overturn of a suspension layer was not observed in the case of cooling from above, but a critical value of particle concentration separates a regime of no overturn at all from a regime of continuous overturn.

\section{Regime of no overturn}

When the particle concentration was sufficiently large, a sharp interface was observed between a convecting upper clear region and a non-convecting lower region in which there was unimpeded sedimentation. The thickness of the interfacial zone increased, in a manner similar to that found in the experiments of heating from below. There were two components driving convection in the upper layer. The fluid in the upper layer was cooler and denser than the warmer, and hence buoyant, fluid incorpoarted into the base of the upper layer as the interfacial zone descended. This effect supplemented the convection driven by cooling from the top itself. Because of the con- vection in the upper layer, there was mixing of both buoyant fluid and entrained particles from the uppermost part of the interfacial zone into the upper layer; however, there was no transport of fluid from the upper region to the lower in agreement with the experimental observations reported by Huppert et al. (1991). A typical temperature evolution of this regime is shown in Figure 9a. The temperature of the upper layer, $T_{\mathrm{U}}$, began to decrease immediately after the cold plate was positioned in contact with the fluid at the top of the tank. However, the initial decrease in temperature was insufficient for the density of the upper layer to exceed that of the particle-laden layer beneath. Thereafter, as the interfacial zone descended, fluid at the initial temperature was incorporated into the upper layer and resulted in an increase of the temperature of the upper layer. The temperature of the upper layer reached a quasi-steady value, suggesting that the heat loss from the cold plate and the heat carried by incorporated fluid were balanced. The temperature of the lower layer remained constant, which supports the qualitative observation that the lower layer was stagnant and the process of sedimentation in this layer was unaffected by the convective motions in the upper layer.

\section{Regime of continuous overturn}

When the particle concentration was sufficiently small, the fluid in the very thin upper layer initially generated was cooled sufficiently for its density to exceed that of the lower layer and continuous overturn occurred virtually from the beginning of the experiments. The evolutions of the temperature and particle concentration then followed the same path as for experiment A. A typical temperature evolution for this regime is shown in Figure $9 \mathrm{~b}$.

The transition between the two regimes of no overturn and continuous overturn was somewhat gradational. In this transitional regime, wavy motions were observed at the interfacial zone driven by the convective motion 

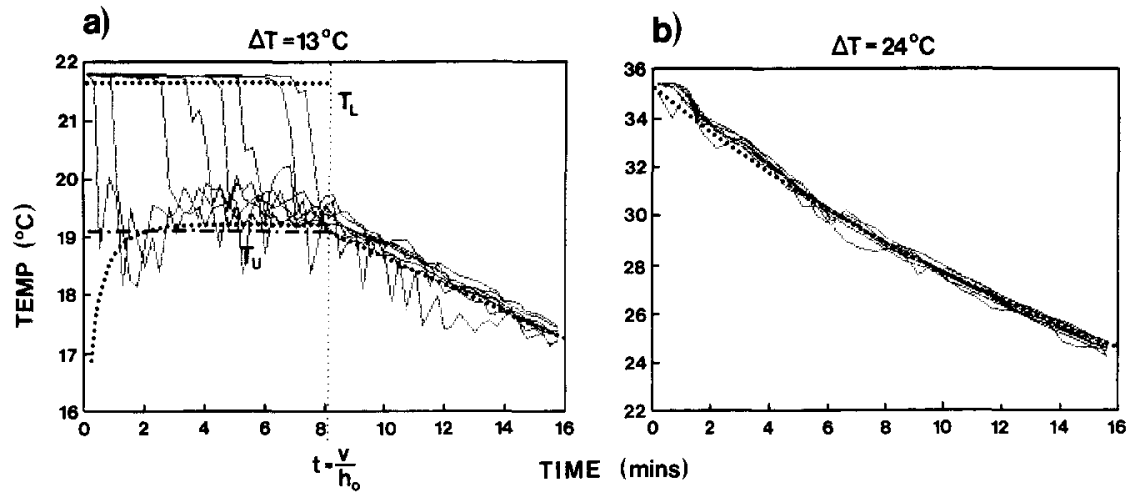

Fig. 9. Representative temperature evolutions for the two different regimes found in experiments cooled from above. In each case $\mathrm{C}_{\mathrm{o}}=0.292 \mathrm{wt} . \%$. a) No overturn regime with $\Delta T=13^{\circ} \mathrm{C}$. Theoretical values of $T_{\mathrm{U}}$ given by numerical integration of equations (15) and (17) for $0<t<h_{0} / v$ and $T$ given by equation (19) for $h / v<t$ are superimposed as dotted curves. The theoretical steady-state solution to equation (18) is also shown as a dot-dashed line. b) Continuous overturn regime with $\Delta T=24^{\circ} \mathrm{C}$. Theoretical evolution of $T$ from equation (19) is shown as a dotted curve.

in the upper layer and the rate of entrainment of particles from the interfacial zone into the upper layer became significant. This effect resulted in an increase in the descent rate of the interface. In Figure 10 the descent rates of the top and bottom of the interfacial zone are plotted against initial particle concentration for different values of $\Delta T\left(\Delta T=0,13\right.$, and $\left.24^{\circ} \mathrm{C}\right)$. The descent rate is independent of the particle concentration when $\Delta T=0^{\circ} \mathrm{C}$, because the particle concentration is sufficiently small for the effects of hindered settling as described by Batchelor (1972) to be negligible. In the experiments with $\Delta T=13^{\circ} \mathrm{C}$, the descent rate is

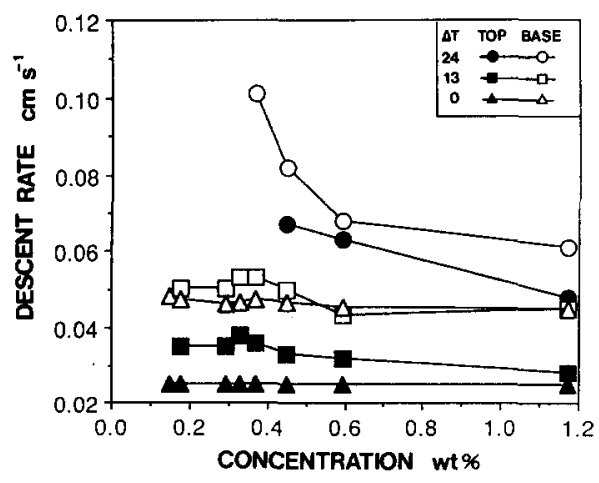

Fig. 10. The descent rate of the interfacial zone as a function of particle concentration, for experiments cooled from above. constant for a particle concentration in excess of $0.5 \mathrm{wt} . \%$. The rate is slightly greater than those of experiments conducted with $\Delta T=0^{\circ} \mathrm{C}$. This difference is explained by higher initial temperatures and hence lower fluid viscosities in the experiments at $\Delta T=13^{\circ} \mathrm{C}$. The descent rate of the interface increases due to entrainment by convection at lower particle concentrations $(0.6-0.18 \mathrm{wt} . \%)$ while continuous overturn was observed at initial particle concentrations less than $0.15 \mathrm{wt} . \%$. In the experiments with $\Delta T=24^{\circ} \mathrm{C}$, the descent rate of the interface increased as the particle concentration decreased from 0.6 to $0.37 \mathrm{wt} . \%$ and the continuous overturn was observed at particle concentrations less than $0.3 \mathrm{wt} . \%$.

\section{Theoretical model}

A heat budget calculation for the upper layer, which incorporates both the removal of heat, $q_{T}$, through the top cooling plate and the incorporation of fluid from the lower layer, leads to:

$\rho_{\mathrm{F}} \mathcal{C}_{\mathrm{P}} \frac{\mathrm{d}}{\mathrm{d} t}\left[v t\left(T_{\mathrm{U}}-T_{\mathrm{o}}\right)\right]=-q_{\mathrm{T}}$

The heat flux to the top plate can be expressed as (c.f. equation 4 ): 
$q_{\mathrm{T}}=\rho_{\mathrm{F}} \mathcal{C}_{\mathrm{P}} \gamma\left(\frac{\alpha g \kappa^{2}}{\nu}\right)^{1 / 3}\left(T_{\mathrm{U}}-T_{\mathrm{A}}\right)^{4 / 3}$

The lower layer remains at the constant temperature $T_{0}$ for all time. Unfortunately, if $T_{\mathrm{A}}$ is taken to be a constant in equation (16) there is no solution to equation (15) that is consistent with the necessay initial value condition:

$T_{\mathrm{U}}=T_{0} \quad(t=0)$

Physically, this expresses the fact that it is impossible to withdraw a non-zero amount of heat from a layer of zero thickness. Rather, $q_{\mathrm{T}}$ is initially zero and will build up to the value represented by (16). Given any expression for $q_{\mathrm{T}}$ that is zero initially and rises to the value represented by (16), equations (15) and (17) can be integrated numerically. The results of such a proceedure are shown in Figure 9a and are seen to compare well with the experimental data and the temperature has settled down to the steady-state predicted theoretically below. All solutions attain a steady state, which from (15) and (16) can be seen to be given implicitly by:

$T_{\mathrm{U}}=T_{0}-\frac{\gamma}{v}\left(\frac{\alpha g \kappa^{2}}{\nu}\right)^{1 / 3}\left(T_{\mathrm{U}}-T_{\mathrm{A}}\right)^{4 / 3}$

where $T_{\mathrm{A}}<T_{\mathrm{U}}<T_{0}$. The values of $T_{\mathrm{U}}$ calculated using (18) show excellent agreement with the experimentally observed steady-state temperatures in the upper layer for $t<h / v$, the time taken for the interface to reach the bottom. The temperature evolution of the homogeneous system, for both the regime of no overturn for $t>h / v$ and for the regime of continuous overturn, is described by:

$T=T_{\mathrm{A}}+\left[\left(T_{0}-T_{\mathrm{A}}\right)^{1 / 3}+\frac{\gamma t}{3 h}\left(\frac{\alpha g \kappa^{2}}{\nu}\right)^{1 / 3}\right]^{-3}$

This relationship is also shown in Figure 9a and is also seen to compare well with the experimental data.

The two-layer structure will only be stable if the density of the cold, clear upper layer is less than the bulk density of the suspension in the lower layer which is at a constant temperature. Evaluating the densities using equations (9), (10) and (18), we find that the structure is stable provided that:

$C>\frac{\rho_{\mathrm{P}}}{\rho_{\mathrm{P}}-\rho_{0}} \alpha\left(T_{0}-T_{\mathrm{U}}\right)$

where $\rho_{0}$ is the density of the fluid at $T=T_{0}$, on the assumption that $C \ll 1$. For values of $C$ greater than the critical value determined by (20) the interface is predicted to descend continuously to the bottom which is reached in a time $t=h / v$. For values of $C$ less than this, there will be continual overturn, just as described for experiment $\mathrm{A}$. For values of $\Delta T=T_{0}-T_{\mathrm{A}}$ of $13^{\circ} \mathrm{C}$ and $24^{\circ} \mathrm{C}$ we evaluate $T_{U}$ using (18) to be 19 and $31.5^{\circ} \mathrm{C}$, with a stability boundary

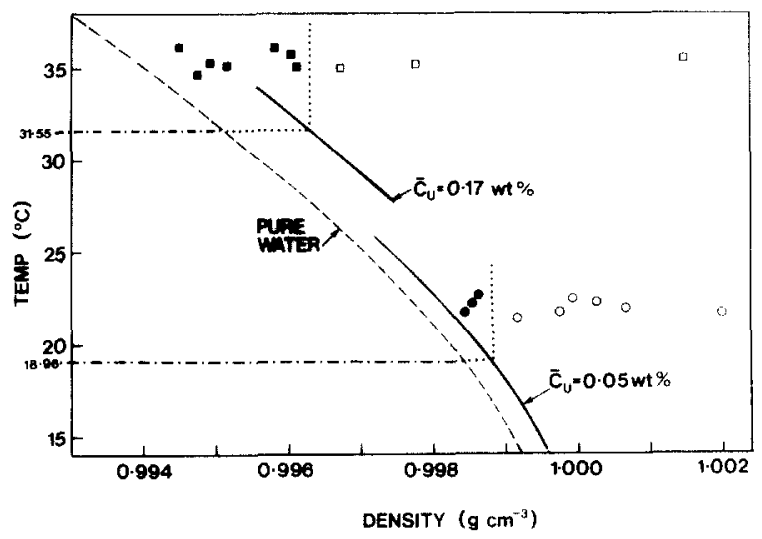

Fig. 11. Plot of density as a function of temperature for experiments cooled from above. Data points show the bulk density of the initial suspensions for various concentrations calculated using equation (9) at two different initial temperatures, $T_{0}$, of $\approx 22^{\circ} \mathrm{C}(O)$ and $\approx 36^{\circ} \mathrm{C}(\square)$. These points thus represent the density of the lower layer throughout each experimental run. Solid symbols represent experiments which exhibited continuous overturn, and open symbols represent those in which no overturn occured. The variation of density as a function of temperature is plotted as a dashed curve for pure water, and as solid curves for the addition of 0.17 and $0.05 \mathrm{wt} . \%$ particles. These allow the transition density of the upper layer to be read given the average steady-state temperature of the upper layer, $T_{\mathrm{U}}$, from equation (18), as marked in the diagram. 
evaluated from (20) of 0.090 and 0.238 wt. $\%$ respectively. The agreement between these predictions and our experiments is shown in Figure 11 . The observed discrepancy between the experimental and theoretical transition between the two regimes is explained by the fact that in the experiments the upper layer was not completely clear but contained particles entrained from the upper surface of the interface. Experimentally measured average values for the upper layer concentration $\left(\overline{C_{\mathrm{u}}}\right)$ were 0.05 wt. $\%$ for $\Delta T=13^{\circ} \mathrm{C}$, and 0.17 wt. $\%$ for $\Delta T=24^{\circ} \mathrm{C}$. Figure 11 plots curves of density against temperature for pure water (- - ), $\left(\overline{C_{\mathrm{u}}}=0.05 \mathrm{wt} . \%\right.$ and $0.17 \mathrm{wt} . \%(-)$, obtained from equation (9). Using these modified curves, we find that the theoretical transition agrees very well with the experiments.

\section{Geological implications}

Our experiments have been carried out in a simplified system. Several potentially important limitations should be borne in mind when applying the results to geological situations such as crystal settling in magma chambers. Nevertheless, we can make some positive geological inferences.

The most important difference between these experiments and a crystallizing magma chamber is the driving force of convection. Convection in our experiments was driven either by heating from below or by cooling from above, whereas the driving force of convection in a magma chamber is considerably more complicated. In a magma chamber heat is lost mainly through the roof, while crystallization can take place at both the roof and the floor (e.g., Martin et al., 1987; Worster et al., 1990). The convection can be driven by both thermal and compositional contributions at the roof and the floor. Another important difference between the natural and experimental system is the particle distribution. In our experiments the particles were initially uniformly distributed and there was no change in the number or size of the particles. On the other hand crystals can nucleate and individual crystals can grow during settling in magma chambers.

It is premature as yet to present a fully quantitative model incorporating all the conditions relevant to magma chambers because of the above differences between the experimental and natural systems. However, the experimental results yield the qualitatively important geological implication that the style of convection can be considerably changed when the dimensionless increase in bulk density due to the presence of particles, $C \Delta \rho / \rho_{\mathrm{P}}$, is greater than the dimensionless decrease in fluid density, $\alpha \Delta T$. It is believed that this rule is applicable regardless of the driving forces of convection. In a mafic magma, dimensionless increases in bulk density become larger as the amount of suspended phenocrysts increases. According to Martin et al. (1987), the driving force of convection for mafic magmas is predominantly a compositional change during crystallization. In the case where the crystallizing phase is olivine only, the dimensionless density decrease (i.e. the density decrease due to compositional and temperature changes divided by the magma density at a standard state) at the floor is up to $10^{-3}$. Taking this value, we find that $0.5 \mathrm{wt} . \%$ of olivine phenocrysts would result in an increase in bulk density greater than the decrease in fluid density due to crystallization. It is thus suggested that even small concentrations of phenocrysts have significant influence on the convective motion in a magma chamber and the style of convection for phenocryst-laden magmas cannot be predicted simply by the knowledge of the dimensionless parameters such as Rayleigh number and Prandtl number.

Another important implication of the experimental results is that the size distribution of suspended particles influences convective motion and heat transfer in a magma chamber, although we have no quantitative theory to describe it as yet. If magma crystallizes different minerals (e.g., ferro-magnesian minerals and feldspars), the distribution of terminal veloci- 
ties of these crystals can be polymodal due to the different densities of these minerals. This polymodal distribution in terminal velocity will give the same effect on the convective motion as that of polymodal size distribution. Repetitive overturns may occur, corresponding to each mode of terminal velocities of phenocrysts. Because the rate of sedimentation to the floor of each mineral will drastically change every time the overturn occurs, the overturns should affect the modal abundance of each mineral in cumulative rocks.

The principal motivation in this study was to uncover new phenomena in convecting magma. Moreover, we believe that the phenomena observed in the experiments are sufficiently general that they should be relevant to the explanation of geological or volcanological phenomena, such as sedimentation from turbulently convecting eruption columns or pyroclastic flows. The present result suggests that the convective motion in an eruption column and the bulk fluid motion would be largely affected by the presence of sedimenting particles.

\section{Acknowledgements}

We wish to thank Professor R.S.J. Sparks and Tsukasa Nakano for helpful reviews on earlier versions of this manuscript. The experiments were carried out while Tak Koyaguchi was a Visiting Fellow at the Department of Earth Sciences and Department of Applied Mathematics and Theoretical Physics, University of Cambridge. The research of Mark Hallworth and Herbert Huppert is supported by grants from the NERC and Venture Research International.

\section{References}

Batchelor, G.K., 1972. Sedimentation in a dilute dispersion of particles. J. Fluid Mech., 52: 245-268.

Carrigan, C.R., 1987. The magmatic Rayleigh number and time dependent convection in cooling lava lakes. Geophys. Res. Lett., 14: 915-918.

Davis, R.H. and Hassen, M.A., 1988. Spreading of the in- terface at the top of a slightly polydisperse sedimenting suspension. J. Fluid Mech., 196: 106-134.

Denton, R.A. and Wood, I.R., 1979. Turbulent convection between two horizontal plates. Int. J. Heat Mass Trans., 22: 1339-1346.

Huppert, H.E., 1991. Buoyancy-driven motions in particle-laden fluids. John Miles 70th Birthday Symposium Volume, pp. 141-160.

Huppert, H.E., Kerr, R.C., Lister, J.R. and Turner, I.S., 1991 Convection and particle entrainment driven by differential sedimentation. J. Fluid Mech., 226: 349369.

Huppert, H.E. and Sparks, R.S.J., 1980. The fluid dynamics of a basaltic magma chamber replenished by influx of hot, dense ultrabasic magma. Contrib. Mineral. Petrol., 75: 279-289.

Jones, K.P.N., McCave, I.N. and Petel, P.D., 1988. A computer-interfaced sedigraph for modal size analysis of fine-grained sediment. Sedimentology, 35: 163-172.

Katsaros, K.B., Lille, W.J., Businger, J.A. and Tillman. J.E. 1977. Heat transfer and thermal structure in the interfacial boundary layer measured in an open tank of water in free turbulent convection. J. Fluid Mech., 83: $311-335$.

Koyaguchi, T., Hallworth, M.A., Huppert, H.E. and Sparks, R.S.J., 1990. Sedimentation of particles from a convecting fluid. Nature, 343: 447-450.

Marsh, B.D., 1981. On the crystallinity, probability of occurrence, and rheology of lava and magma. Contrib. Mineral. Petrol., 78: 85-98.

Marsh, B.D. and Maxey, M.R., 1985. On the distribution and separation of crystals in convecting magma. J. Volcanol. Geotherm. Res., 24: 95-150.

Martin, D. and Nokes, R.I., 1988. Crystal settling in a vigorously convecting magma chamber. Nature, 332: 534536.

Martin, D. and Nokes, R.I., 1989. A fluid dynamic study of crystal settling in convecting magmas. J. Petrol., 30: 1471-1500.

Martin, D., Griffiths, R.W. and Campbell, I.H., 1987. Compositional and thermal convection in magma chambers. Contrib. Mineral. Petrol., 96: 465-475.

Sparks, R.S.J., Huppert, H.E. and Turner, J.S., 1984. The fluid dynamics of evolving magma chambers. Philos. Trans. R. Soc. London, Ser. A, 310: 511-534.

Stommel, H., 1949. Trajectory of small bodies sinking slowly through convecting cells. J. Mar. Res., 8: 24-29.

Turner, J.S., 1973. Buoyancy Effects in Fluids. Cambridge University Press, $368 \mathrm{pp}$.

Weinstein, S.A., Yuen, D.A. and Olson, P.L., 1988. Evolution of crystal-settling in magma chamber convection. Earth Planet. Sci. Lett.. 87: 237-248.

Worster, M.G., Huppert, H.E. and Sparks, R.S.J., 1990. Convection and crystallization in magma cooled from above. Earth Planet. Sci. Lett., 101: 78-89. 